\title{
Shared space - research, policy and problems
}

Simon Moody MSC

Transport Planner, WSP UK Ltd, Cambridge, UK
Steve Melia PhD

Senior Lecturer, Centre for Transport \& Society, University of the West of England, Bristol, UK

Shared space is an approach to street design which minimises demarcations between vehicles and pedestrians. It has become particularly influential in the UK, where a comprehensive study of shared space schemes has informed recently published national guidance to local highway authorities. This paper critically examines the claim made in the guidance that it is 'evidence based'. Primary research reported in the paper examines one of the sites in the 'official study' in Ashford, Kent, in greater depth, using video observation and a street survey of pedestrians. The findings show that most pedestrians diverted away from their desire lines, gave way to vehicles in most cases and felt safer under the original road layout. This evidence, and the analysis of the 'official study', cast doubt on some aspects of the methodology and its interpretation in the national guidance. The authors conclude that some of the claims made on behalf of shared space have overstated the available evidence, and that caution is needed in implementing shared space schemes, particularly in environments of high traffic flows.

\section{Introduction}

The concept of 'shared space' between vehicles and pedestrians in streets is becoming increasingly influential across several countries, particularly in Europe (Hamilton-Baillie, 2008; Shared Space, 2011). Its origins are generally associated with the late Hans Monderman, a traffic engineer who pioneered the approach in the Dutch province of Friesland. But the concept has achieved most influence in the UK, where the DfT (2011) has recently published the most comprehensive study yet of shared space sites (MVA Consultancy, 2010a, 2010b) to coincide with new national guidance (DfT, 2011) on shared space for local highway authorities.

The use of those research findings in drafting that guidance appears at first sight an exemplary instance of evidence-based policy, but as this paper will demonstrate, some of the claims made in the guidance are not supported by the evidence. This paper will begin by considering the definitions of shared space and the claims made for it. It will briefly review the literature and focus on the claims of evidence-based policy in the UK. Primary research described in this paper focuses in greater depth on one of the sites also studied by MVA Consultancy (2010a, 2010b). The implications of this analysis - and the gaps in current research knowledge - for policy on shared space, and its implementation will be discussed in the final section. It will conclude that some of the claims made on behalf of shared space have overstated the available evidence, and that caution is needed in implementing shared space schemes, particularly on streets or junctions with high traffic flows.

\section{Definitions of shared space}

There is no agreed definition of 'shared space'. Some writers have described it as a design approach (or philosophy: Shared Space, 2011). The recent UK Government guidance follows advocates such as Hamilton-Baillie in defining shared space aspirationally

A street or place designed to improve pedestrian movement and comfort by reducing the dominance of motor vehicles and enabling all users to share the space rather than follow the clearly defined rules implied by more conventional designs.

(DfT, 2011: p. 6)

This is followed by a list of 'tangible indicators of sharing' such as 'pedestrians sharing the carriageway'. This approach is problematic: if a shared space design fails to improve pedestrian movement should it still be considered a shared space?

MVA Consultancy (2010a) proposes a 'shared space rating' based on observable characteristics (e.g. presence or absence of kerbs, crossing points, road markings etc.). This more sophisticated approach can still be questioned on the same grounds. For the rest of this paper, the term 'shared space' will be used to describe streets designed to minimise demarcations between vehicles and pedestrians - regardless of behavioural outcomes.

\section{Claims made for shared space}

Shared space as a concept was originated by Dutch traffic engineer Hans Monderman and the Keuning Institute (Gerlach et al., 2008). Monderman's original aims were to reduce accidents and congestion and to increase the flow of traffic. There was no expectation of any effect on modal share (personal communication, H. Monderman, 2007). It should also be noted that the Dutch towns where the first shared space schemes were implemented (see Figure 1) also have a high degree of segregation between soft modes and general traffic (e.g. Figure 2), designed to protect and to give a distance/time advantage to these modes. 


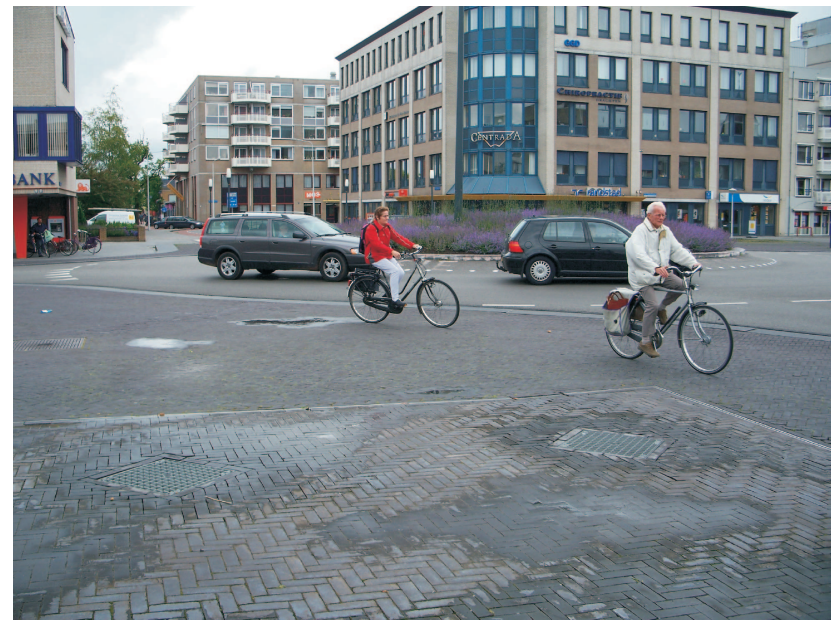

Figure 1. Laweiplein, Drachten, the Netherlands

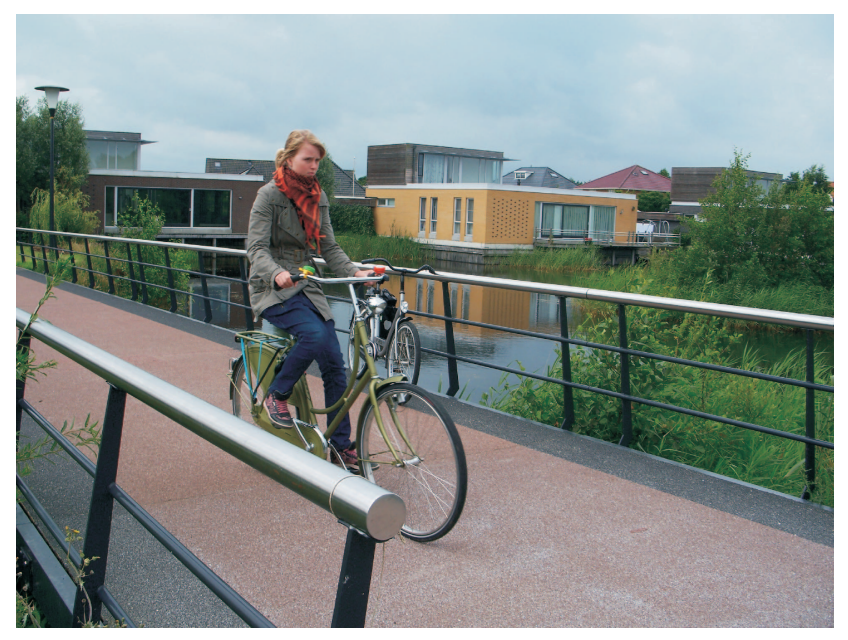

Figure 2. Cycle bridge, Drachten, the Netherlands

In transposing Monderman's ideas to an audience outside the Netherlands, UK-based advocates of shared space removed the corollary about separation of soft modes and added to the list of claims made for it, presenting it as a key policy combining aspirations for: 'efficient traffic circulation, modal shift to walking and cycling, enhancement to the public realm and improved health' (Hamilton-Baillie, 2008: p. 137). Reviewing experience in the UK, MVA Consultancy (2009) found that shared space schemes were implemented for a range of purposes including the following

(a) improving the urban environment

(b) giving people freedom of movement rather than instruction and control

(c) improving the ambience of places

(d) enhancing social capital

(e) enhancing the economic vitality of places.
These claims appear to have been made in advance of any systematic evidence to support them, as reviewed in the next section. Manual for Streets (DfT, 2007), design guidance for residential streets in the UK, recommended that shared space was only appropriate in streets with low traffic volumes. Manual for Streets 2 - which extended the principles of the earlier guidance to mixed-use streets - removed this caveat about traffic volumes, and suggested that shared space might be a 'more desirable' alternative to pedestrianisation in some contexts (CiHT, 2010). This approach raises a number of issues, not all of which can be addressed here, but clearly depends upon the validity of the claims that shared space designs create significant improvements for pedestrians (however 'improvements' are defined and measured).

\section{Research evidence on pedestrians in shared space streets}

Given the focus of shared space on pedestrians, it is striking how little research had been done until very recently on pedestrian behaviour and attitudes in shared spaces. Whereas a substantial literature exists on street design and pedestrian and driver behaviour generally, academic research evidence on shared space is currently limited. A literature search revealed that most of the evidence so far has been in the form of consultants' reports, conference papers, student dissertations or reports for organisations which support or oppose aspects of shared space (e.g. Childs et al., 2010; Shared Space, 2011). Work is under way in developing a model of the interaction between pedestrians and vehicles in shared spaces (Anvari, 2012); this work is at an early stage.

Much of the available evidence focuses on accident statistics and traffic flows. Advocates of shared space have provided largely descriptive accounts of benefits from existing schemes (e.g. Hamilton-Baillie, 2008) while opponents have questioned whether the reductions in accidents observed in some (though not all) sites were achieved partly through intimidating pedestrians (Methorst, 2007).

In 2007 the NHL, University of Applied Sciences conducted a study of The Laweiplein in Drachten, the Netherlands (Figure 1). The scheme, implemented by Hans Monderman in 2000, is estimated to accommodate approximately 22000 vehicle movements per day and is often cited as a leading example of shared space. The survey work was undertaken before and after the scheme implementation, using a combination of traffic flow data, video analysis and questionnaires. The study concluded that the area as a whole had improved, with fewer accidents and less delay for both pedestrians and vehicles (NHL, 2007). Although the overall findings were positive, it found most still preferred to use the informal courtesy crossings and that some pedestrians tended to 'hurry' across the space (NHL, 2007). Only $9 \cdot 7 \%$ and $13 \%$ of participants surveyed in the before and after studies were pedestrians, so this study provides limited insight into the effect of the scheme on pedestrians. Gerlach et al. (2008: p. 10) comment that conversion from a crossroad to a roundabout in this 
context would have reduced traffic speeds, and hence serious accidents, in any case. They conclude that 'the positive effects on traffic safety ... are neither primarily nor exclusively attributable to the properties of the Shared Space principle' - raising a broader issue about the interpretation of evidence, as discussed later in Sections 6 and 9.

Two studies have used stated preference methods to explore pedestrian attitudes to (hypothetical or illustrated) shared space streets. Kaparias et al. (2012) found that pedestrians feel most comfortable sharing space in conditions which ensure their presence is clear to other road users - that is, conditions involving low vehicular traffic, high pedestrian traffic, good lighting and provision of pedestrian-only facilities. It was found that young men were the most comfortable sharing space, whereas people with disabilities and older people were more negative. Kaparias et al. (2012) produced similar findings, with speed and volume of traffic both significantly reducing the willingness of pedestrians to share space with vehicles. Conversely, the provision of 'safe zones' created by vegetation or street furniture increases the willingness of pedestrians to share space with vehicles.

These hypothetical findings pose the question of whether pedestrians with 'real life' experience of shared space schemes would react in a similar way. In March 2010 Bristol City Council conducted an experiment into the value of traffic management by switching off traffic lights at two sites within the city. This enabled a study of the willingness of pedestrians to share space with vehicles (Firth, 2011). Vehicle flows were relatively high: around 600 two-way movements per hour. Pedestrians' attitudes varied across the different sites, but most believed that signal controls were safer and easier to use (Firth, 2011).

\section{The MVA study for the UK Department for Transport}

In 2009 the UK's Department for Transport appointed MVA Consulting to develop 'evidence-based design guidance on shared space highway schemes'. The use of this evidence in the guidance will be discussed in Section 9.

The interim report, which reviewed existing evidence, included several studies of 'home zones' and pedestrian priority zones (MVA Consultancy, 2009). The schemes considered by these studies differed in many respects: in one example (York, 2003 cited in MVA Consultancy, 2009) buses were the only vehicles allowed to share the space with pedestrians. Section 3.2 on economic activity and property values describes one study which suggested a positive relationship between shop vacancy rates and vehicular traffic flows, and others which show positive relationships between commercial property values and 'pedestrian friendly environments' or 'street quality'. It was not clear from this evidence whether the nature and degree of demarcations between vehicles and pedestrians exerted any significant influence on these relationships (a key issue for the final reports).
On the defining issue of pedestrian movement it was noted that 'mixed priority routes' increased pedestrian movement whereas home zones did not. The evidence on casualty rates was mixed, with two Dutch studies suggesting an increased risk at higher traffic volumes (Quimby and Castle, 2006; Zeegers, 2009 cited in MVA Consultancy, 2009). No evidence was presented of any influence on modal shares.

MVA's primary research was based on ten sites selected from across the UK, with a range of vehicle flows, speeds and features such as kerbs and crossing points (MVA Consultancy, 2010a). These features were assessed on a point-scoring system contributing to a 'shared space rating'. This rating was used in various statistical tests, one of which showed a negative association with vehicle speed. In their commentary, the researchers imply that this association demonstrates causality (MVA Consultancy, 2010a, 3.4.6). They did not acknowledge the obvious possibility that vehicle speeds might have (consciously or unconsciously) influenced the extent to which traffic engineers were willing to remove demarcations across the ten sites. Furthermore, the only physical factors included in the model related to the sharing of space. Other measures more explicitly designed to reduce speed, such as the narrowing or deflection of carriageways, were not included. The shared space rating may therefore have been acting partly as a proxy for unmeasured factors such as these.

The researchers also sought to measure 'pedestrian use of space' through a method involving the researchers drawing five 'desire lines' for each site based on observed pedestrian movements. On the basis of just 30 observations, Elwick Square in Ashford was recorded as achieving 100\% movement along desire lines. The validity of this finding will be questioned in Section 9.

Across all the MVA sites, no robust association was found between pedestrian use of space and the shared space rating, although negative associations were found with traffic volumes, kerbs and 'colour contrast between carriageway and footway'. Across most of the sites, pedestrians gave way to vehicles more often than vice versa. Higher vehicle flows were associated with a lower propensity of drivers to give way, whereas higher pedestrian flows were associated with a higher propensity to give way.

The qualitative element of the research suggested that speed and volume of traffic were more important influences on pedestrian experience than demarcations, with some pedestrians preferring shared streets to their conventional controls and vice versa in other locations (MVA Consultancy, 2010b). Interestingly, the researchers did not ask any pedestrians with experience of conversions to shared space for their views on the advantages and disadvantages of the conversions.

Much of the opposition to the concept of shared space in the UK has come from groups representing visually impaired and blind people (Guide Dogs for the Blind, 2011). A chapter of MVA Consultancy (2010b) describes the findings from qualitative inter- 
views with people having a range of disabilities. The authors present this qualitative analysis in a quantitative form, showing graphs based on very small sample sizes. Although they could not be considered statistically valid, these confirm the findings of previous research (Guide Dogs for the Blind, 2011) that people with disabilities, and particularly visually impaired people, generally prefer conventional streets to the shared space streets. People with all types of disability preferred 'wide pavements and quieter streets'. Visually impaired people preferred raised kerbs, whereas other groups preferred a flat surface.

\section{Elwick Square case study}

Elwick Square, in Ashford, Kent, was ranked second of the chosen sites based on MVA's shared space rating. The primary research described here examined that one location in greater depth, raising a number of questions about the methodology, findings and interpretation of MVA Consultancy (2010a, 2010b).

Elwick Square forms the centrepiece of a larger regeneration project which opened in 2008 and won a number of national awards in the UK. The project involved the regeneration of a former one-way ring road which circulated Ashford town centre. The highway layout has been simplified and many conventional highway engineering features have been removed. The southern side of the square has not yet been redeveloped, so this creates an impression of a relatively wide open space.

The ring road now accommodates two-way vehicle movements and is subject to a $20 \mathrm{mph}$ speed limit. There is very little sign of segregation between modes, with all users occupying a largely unmarked level surface (O'Rourke, 2011) with no vegetation or street furniture (apart from lamp standards) in the main part of the square. The square also accommodates traffic flows of approximately 11000 movements per day and up to 850 movements per hour, presenting an opportunity to analyse the use of shared space in an area of high traffic flow (Kent County Council, 2009).

In the previous layout the carriageway formed the central feature of what is now Elwick Square. As shown in Figure 3, traffic signals, road markings, signs, guardrails, kerbs and footways were some of the many features of the previous layout maintaining demarcation between pedestrians and vehicles. Today, as shown in Figure 4, the square incorporates a level surface with no delineation between the carriageway and footway, surfaced with square granite setts rather than conventional tarmac. The space is mainly clear with some landscape features and bespoke street lighting to enhance the design (Coulthard, 2009). Much like the Laweiplein shared space scheme in Drachten, there are informal pedestrian 'courtesy crossings' positioned where each of the carriageways adjoins the square, providing the pedestrian with an option to use an informal type of segregation.

The roads leading to Elwick Square have also been uncluttered and reconstructed as part of the regeneration scheme. A footbridge is located on the southern edge which provides an

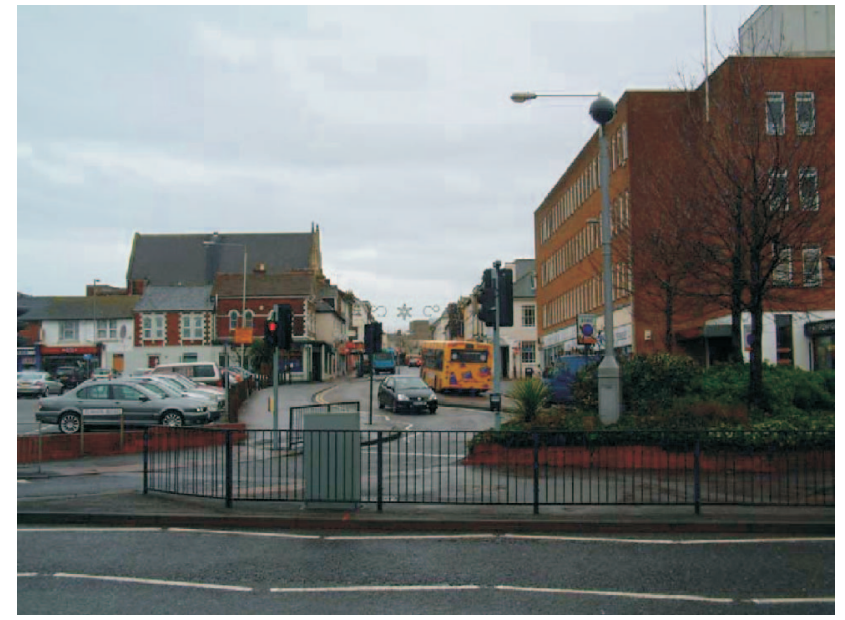

Figure 3. Elwick Square previous layout

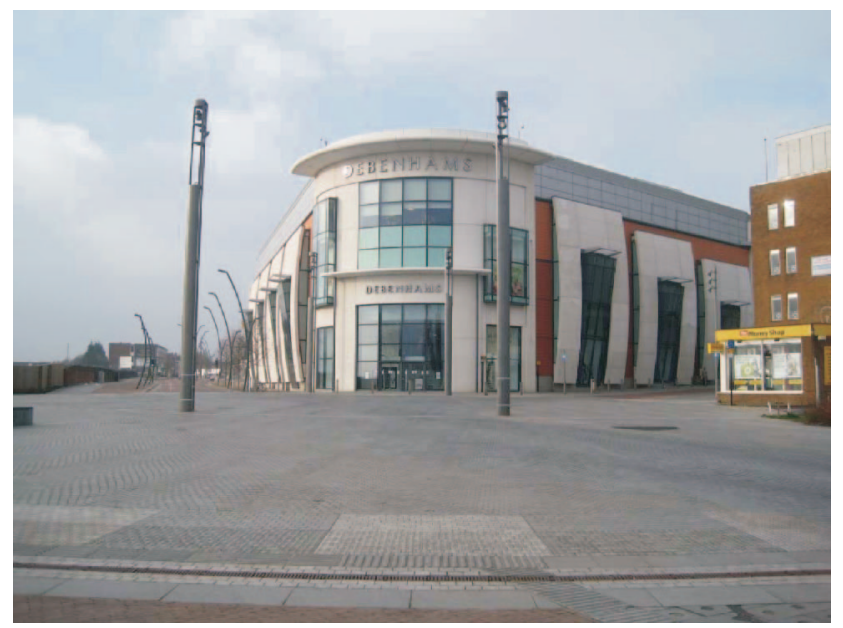

Figure 4. Elwick Square existing layout

important pedestrian link from the residential areas in the south to Ashford town centre to the north of the square.

\subsection{Video observation: pedestrian path-following survey}

The research took place in two phases in early 2011. As in the MVA study, video cameras were used to track pedestrian movements across Elwick Square. These were plotted on an OS base map using a computer-aided design package. To analyse the data, the study area was separated into three 'zones' designed to measure the sharing of the space, as illustrated in Figure 5.

Zone 1 is an area of the square in which pedestrians could fully share space with traffic. Zone 2 is the area which could be covered by pavement in a more conventional street - where pedestrians may segregate themselves from traffic. Zone 3 covers the three 'courtesy crossings' where pedestrians may expect a higher degree of priority over traffic than in zone 1 . The coding 


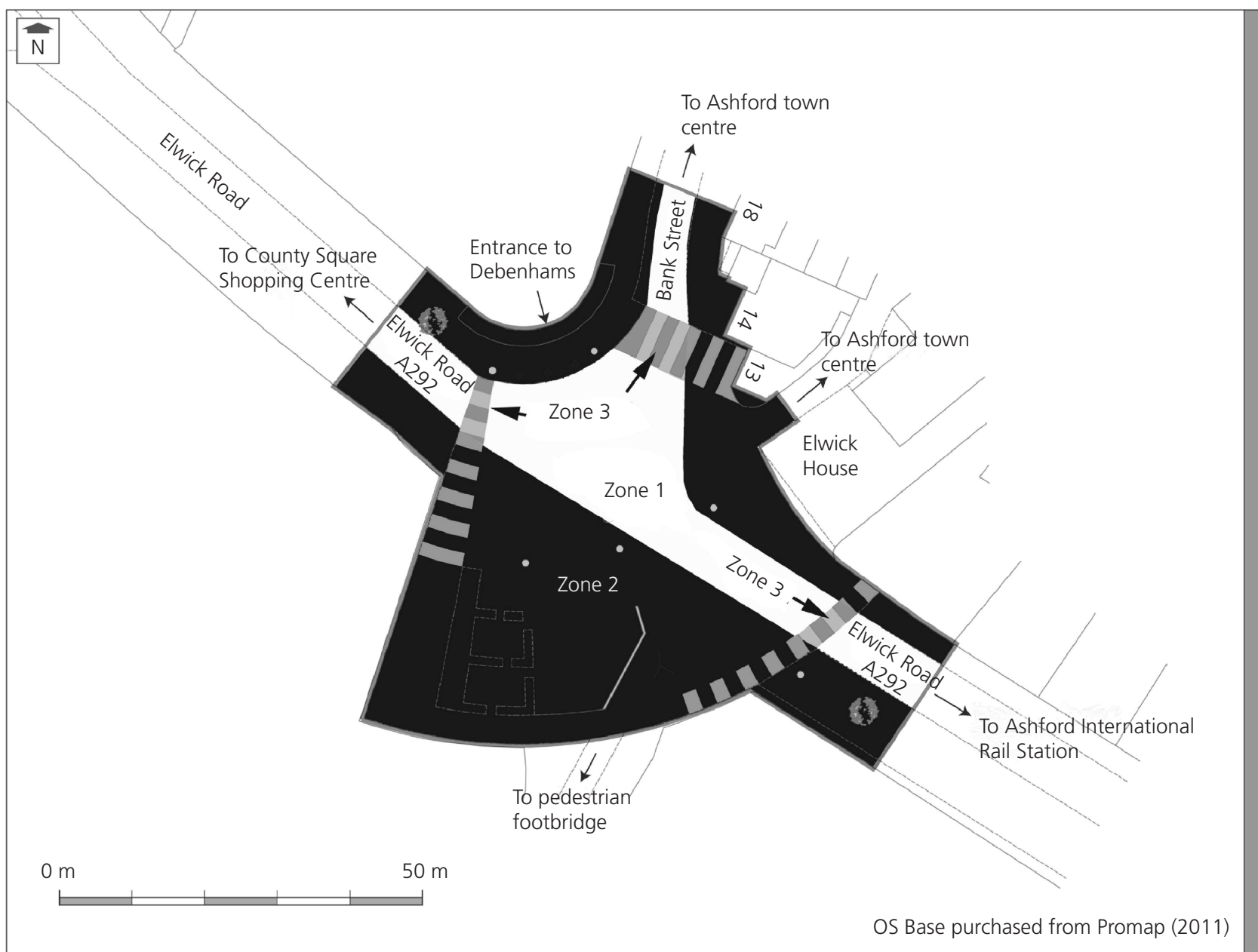

Figure 5. Elwick Square: zones

scheme and the positioning of each zone were identified prior to the undertaking of any pedestrian observations in order to avoid the danger of unconscious bias (Robson, 2002).

A total of 281 pedestrian movements were recorded. Excluding movements entirely within zone 2 reduced this to 179 'crossing movements', on which the analysis below was based; as the main focus was on pedestrians, vehicle movements and speeds were not measured. The survey also recorded 'conflicting movements' when the paths of a vehicle and a pedestrian conflicted, and instances of pedestrians running to cross the space.

\subsection{On-street pedestrian interviews}

A total of 144 semi-structured on-street interviews were also conducted with pedestrians passing through and using Elwick Square on three weekdays. The interviewees were selected by using a systematic probability sample: every fifth person passing through the study area between 08:00 and 18:00. These hours were chosen because traffic flows remained relatively constant between them, ranging from 723 to 863 vehicle movements per hour (Kent County Council, 2009).

\section{Results}

\subsection{Video evidence}

Figure 6 presents a plot of all pedestrian movements obtained from the video tracking. Some $56 \%$ of the crossing movements travelled around the periphery of the scheme. Most pedestrians tended to use the informal 'courtesy crossings', lengthening their route and diverting their desire line away from the natural continuation of the carriageway at the centre of the square.

Most pedestrians only tend to cross 'zone 1' in specific sections, perhaps avoiding the most complex area at the very centre of the square. When travelling on a north-south axis most pedestrians tend to cross 'zone 1' at the shortest point where there is only one stream of traffic, avoiding the centre of zone 1 where all the carriageways meet. The natural desire lines of pedestrians which would pass through that point tend to divert via the informal courtesy crossing to the west.

In $72 \%$ of the conflicting movements, the pedestrian initially gave way to the vehicle. In $20 \%$ of instances the vehicle subsequently 


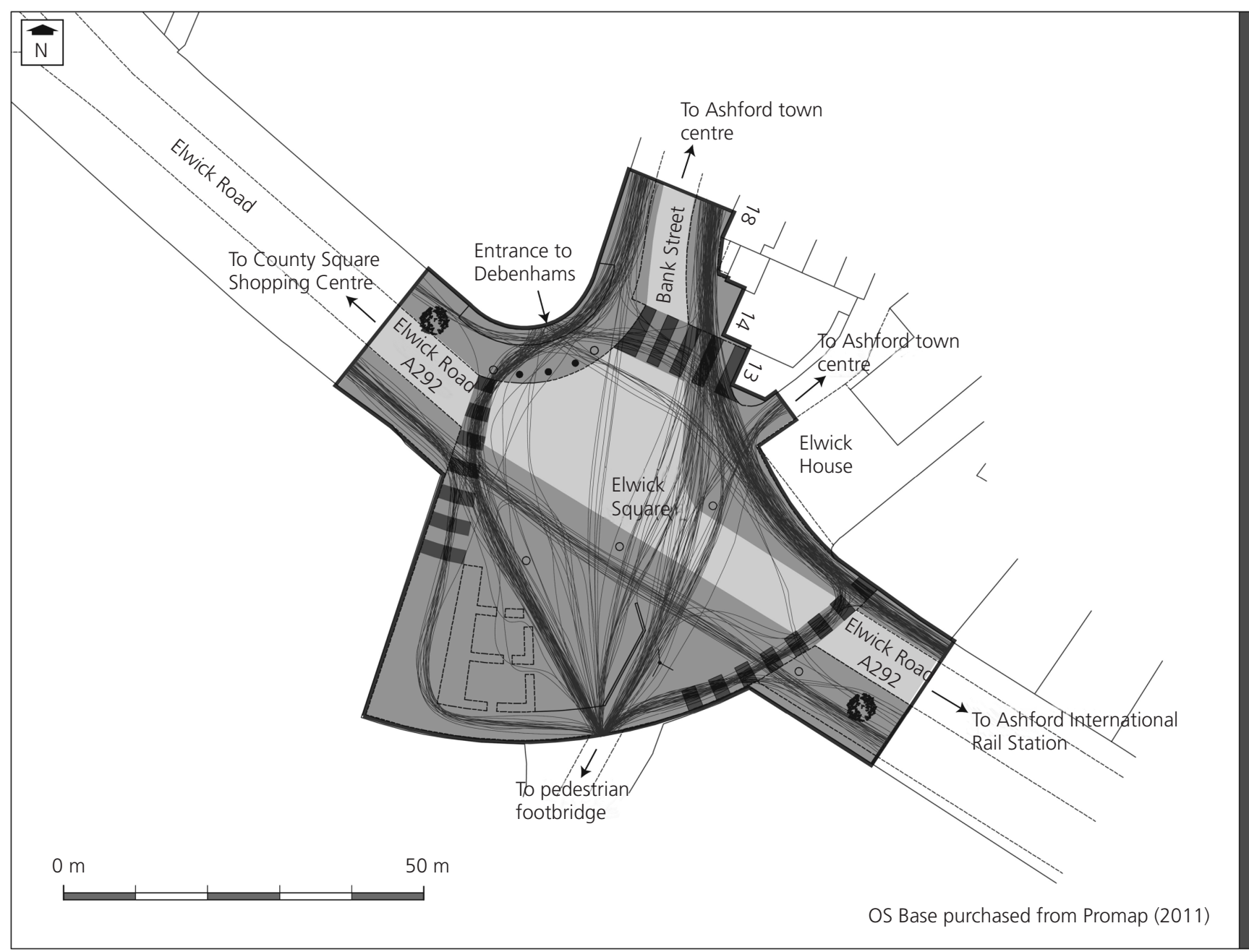

Figure 6. Pedestrian movements observed by video

gave way, leaving $52 \%$ of conflicting movements where the pedestrian waited at the edge of zone 2, until the traffic had moved on. Although most pedestrians treated the courtesy crossings like zebra crossings, most drivers did not treat them in this way, initially giving way in only $37 \%$ of conflicting movements with a pedestrian in zone 3 .

Pedestrians were observed running in $17 \%$ of all the crossing movements. This figure rises to $24 \%$ when looking at pedestrian movements in zone 1 only.

\subsection{Pedestrian interviews}

Table 1 summarises some of the key responses from the questionnaires.

In responses to qualitative questions the most common suggestions for changes to the square were the introduction of formal crossings - signalised or formal zebra crossings. Several interviewees doubted whether the informal crossings were prominent enough for drivers to recognise. Many pedestrians found motor- ists within Elwick Square hostile and unwilling to share space, citing high traffic flow and vehicle speeds as the main cause for anxiety. A number of respondents also spoke of how they deliberately moved around the edges of the square to avoid conflict with traffic. A few participants claimed to know of people who avoided Elwick Square altogether, signifying that levels of anxiety actually prevented certain pedestrians from using the square.

For a long time I avoided the area, but I think I'm becoming more used to it now, but in the mornings getting to work must be a nightmare because of all the traffic. I don't know what the younger people think of it but I know older people who don't come through here, including me at first.

Several parents expressed anxiety about their children using the space, for example

I'm worried about my child too who goes to school over there, I won't let him go on his own now. I don't tend to cross the middle. It might 


\begin{tabular}{|c|c|c|c|c|}
\hline & Yes & No & $\begin{array}{l}\text { Don't } \\
\text { know }\end{array}$ & $n$ \\
\hline Are you ever worried about sharing space in Elwick Square? & $72 \%$ & $23 \%$ & $5 \%$ & 144 \\
\hline In this type of setting would you prefer traditional pavements and traffic light crossings? & $64 \%$ & $29 \%$ & $7 \%$ & 144 \\
\hline Do you view this square as an area in which you can stop and socialise? & $33 \%$ & $65 \%$ & $2 \%$ & 144 \\
\hline \multirow[t]{2}{*}{ As a pedestrian would you make any changes to the layout of Elwick Square? } & $74 \%$ & $24 \%$ & $2 \%$ & 144 \\
\hline & Yes & No & Same & $n$ \\
\hline \multirow[t]{2}{*}{ As a pedestrian did you feel safer in the previous scheme? } & $80 \%$ & $14 \%$ & $6 \%$ & 124 \\
\hline & More & Less & Equal & $n$ \\
\hline As a pedestrian, do you feel you have more, less or equal priority over vehicles? & $19 \%$ & $78 \%$ & $3 \%$ & 144 \\
\hline
\end{tabular}

Table 1. Responses from pedestrian interviews

be alright for locals and people who know what's going on, but I know quite a few people who like to avoid the area, they take a longer way just to get into the centre.

Of the people interviewed, $90 \%$ had experienced the previous scheme and $80 \%$ claimed they felt safer in the previous layout. A few interviewees preferred the new scheme, however, both in terms of its aesthetics and usability

I feel safer here in this one, it's more open now, helps you see the traffic so you can cross a lot easier.

Important demographic differences were found in pedestrian attitudes towards Elwick Square. The following comparisons, using chi-square tests, were all significant at the 95\% level. Men were less likely to be anxious about sharing space with traffic in Elwick Square, with only $58 \%$ of men reporting anxiety in comparison to $91 \%$ of women. Men were less likely to prefer traditional segregation and less likely to want to make changes to the existing layout of the square. Males were found to be more likely to believe they had equal or more priority to the car, with $98 \%$ of women believing they had less priority in comparison to $63 \%$ of men. Men were more likely to view Elwick Square as a place in which they could socialise with other pedestrians.

People in the youngest age category $(18-30)$ were more likely to have adapted to certain aspects of Elwick Square. For example it was found that they would be more likely to view the square as a place for social interaction (46-95\% confidence) and that they were more likely to believe they had equal or more priority to the car.

Finally, people who used the scheme on a daily basis were more likely to want to make changes to the layout (83\%) than those who used it less than once a week (56\%).

\section{Analysis}

The DfT states that its guidance is 'evidence-based' drawing on the MVA research (DfT, 2011). There are no footnotes or specific references to verify the source of each statement but some appear well supported; others are contestable. The statement that 'key factors affecting pedestrian comfort in shared space appear to be volume, type and speed of traffic' is well supported by evidence, as is much of the section entitled 'Detailed design'.

The statement that 'reducing demarcation ... and formal traffic management features tends to reduce speeds' (DfT, 2011, 3.2.6), if based on the MVA research, confuses association with causality, as discussed in Section 6. Clearly some street design measures can reduce speed but whether reducing demarcations in itself reduces speed, under some, all, or no circumstances is difficult to ascertain from existing evidence. This point applies to several of the claims made for shared space. The evidence on economic benefits discussed in Section 5 relates to vehicle speeds and 'pedestrian friendliness' but not to shared space per se.

The assertion that shared space streets have 'a comparable number of casualties' to conventional streets in DfT (2011) is a political statement, ignoring the findings discussed in MVA Consultancy (2009) which suggested that at higher traffic flows the risk may increase. The concept that removing demarcations reduces the risk of collisions and casualties seems counterintuitive. Several of the studies reviewed here, including MVA Consultancy (2010b), support the observation that risk reduction in shared spaces is largely achieved through the creation of anxiety or 'unease' among drivers and (as the case study demonstrates) pedestrians. In the UK, and even in those parts of the Netherlands where the concept was pioneered, shared space schemes are relatively new, and a departure from the normal expectations of road users. If shared space becomes the norm in some areas or circumstances, this raises the question of whether this unease might begin to diminish in the longer term, entailing an increase in collisions and casualties.

The guidance amplifies the assertion in MVA Consultancy (2010a) that reducing demarcations encourages people to 'move more freely' and 'follow desire lines'. The case study described in this paper poses some questions about the methodology which led to that conclusion. As described in Section 7 above, the three zones in this study were defined before data collection began, in 
order to avoid the dangers of unconscious bias identified in the methodological literature. In MVA Consultancy (2010a), the researchers defined the desire lines ex-post based on observations of pedestrian movements. Using this method, MVA Consultancy (2010a) found that $100 \%$ of pedestrians crossing Elwick Square followed their desire lines, whereas the case study described in this paper found that most pedestrians were clearly diverting from their desire lines - using the courtesy crossings in most cases (see Figure 6). The survey responses suggest that this was mainly motivated by concern to minimise conflict with traffic. Either MVA's much smaller sample (30 movements) was reflecting very different behaviour on a different day (possibly with different levels of traffic flow) or the 'desire lines' were defined in ways which allowed for pedestrians diverting their paths to minimise contact with moving vehicles. In either case, the conclusion that removing demarcations encourages pedestrians to move more freely and follow desire lines should be treated with some caution.

MVA Consultancy (2010b) acknowledges some of the negative perceptions of pedestrians towards the shared space scheme in Elwick Square. Traffic volume and a space 'too wide to get across quickly' were two possible reasons why attitudes there were more negative than in the other schemes included in their qualitative research. However, the types of questions shown in Table 1 - particularly the 'before and after' comparison - were generally not asked in MVA Consultancy (2010b). The answers reported here suggest a rather negative pedestrian perspective on a 'flagship' shared space scheme at odds with the aspirational definition of shared space in DfT (2011).

\section{Conclusion}

The primary research in this paper, based on a single site, would in itself provide only a limited basis for generalisation, but several of its key findings are consistent with those of other researchers in different contexts, using different methods. It supports - in a 'real life' context - the findings of Kaparias et al. (2012) that women and older people are generally more negative about shared space. The high traffic volumes and absence of vegetation or street furniture creating the perception of 'safe zones' are both likely to contribute to the negative perceptions of Elwick Square. Some of the 'purer' shared space schemes in the Netherlands were subsequently attenuated - by the introduction of more formal pedestrian crossings, for example (Gerlach et al., 2008), as suggested - unprompted - by a majority of respondents in Ashford.

The Elwick Square research also raises some questions around the 'evidence based policy' contained in DfT (2011). The claims that reducing demarcations reduces vehicle speeds and encourages pedestrians to 'move more freely' are not well supported by the available evidence. Those claims may be true in some circumstances but more specific evidence would be needed to establish what those circumstances might be. Approaches such as that piloted by Anvari (2012) may provide such evidence in future. For highway engineers and transport planners who need to act in the meantime, it would seem that reducing both the speed and volume of traffic is key to achieving pedestrian benefits. These two points are stressed in DfT (2011). Two further points which are not specifically reflected in the guidance emerge from several of the studies reviewed here. They are the benefits of safe zones protected by physical barriers and clearly visible pedestrian crossings, where the volume or speed of traffic suggests a need for a crossing.

Neither the MVA study nor any of the other research reviewed for this project provides evidence to support the assertion of Hamilton-Baillie (2008) that shared space can contribute to modal shift. In the absence of specific research (which would be difficult to frame in situations where small schemes are implemented incrementally over time) it may be noted that one observed outcome of shared space - increased vehicle flows through junctions - would facilitate movement by car. Where shared space is proposed as an alternative to traffic removal through pedestrianisation, for example - it is likely to favour movement by car.

Despite the declared attempt at 'evidence based policy' in DfT (2011), the progression from Manual for Streets (DfT, 2007) through Manual for Streets 2 (CiHT, 2010) and the MVA research to the latest guidance (DfT, 2011) suggests that 'policy based evidence' may also have influenced the process. In other countries, where the vogue for shared space is not as widespread as in the UK, policymakers and professionals would be well advised to approach the concept with caution and a degree of scepticism towards the claims made by its advocates.

\section{REFERENCES}

Anvari B (2012) A mathematical model for driver and pedestrian interaction in shared space environments. Proceedings of the 44th Universities Transport Study Group Conference, Aberdeen, UK, January.

Childs CR, Thomas C, Sharp S and Tyler N (2010) Can shared surfaces be safely negotiated by blind and partially sighted people? Proceedings of the 12th International Conference on Mobility and Transport for Elderly and Disabled Persons (TRANSED), Hong Kong, PR China, 2-4 June.

CiHT (2010) Manual for Streets 2: Wider Application of the Principles. The Chartered Institute of Highways and Transportation, London, UK.

Coulthard T (2009) Adventures in space: is the UK really ready to embrace the principles of shared space in its public realm. Landscape: The Journal of the Landscape Institute 2009(Autumn): 10-20.

DfT (Department for Transport) (2007) Manual for Streets. Department for Transport, Thomas Telford, London, UK.

DfT (2011) Local Transport Note 1/11. Department for Transport, The Stationery Office, Norwich, UK.

Firth K (2011) Removing traffic engineering control - the awkward truth. Transport Engineering and Control 2011(February): 73-79. 
Gerlach J, Methorst R, Boenke D and Levens J (2008) Sense and Nonsense in Shared Space. Feitsberaad, Utrecht, the Netherlands. See http://www.fietsberaad.nl (accessed 01/07/2011).

Guide Dogs for the Blind (2011) Guide Dogs for the Blind Shared Surface Streets Perceived as 'No Go' Areas by Blind and Partially Sighted People Says New National Survey. Guide Dogs for the Blind Association, Reading, UK. See http:// www.guidedogs.org.uk/news/2010/shared-surface-streetsperceived-as-no-go-areas-by-blind-and-partially-sightedpeople-says-new-national-survey/ (accessed 02/11/2011).

Hamilton-Baillie B (2008) Towards shared space. Urban Design International 13(2): 130-138.

Kaparias I, Bell MGH, Miri A, Chan C and Mount B (2012) Analysing the perceptions of pedestrians and drivers to shared space. Transportation Research Part F: Traffic Psychology and Behaviour 15(3): 297-310.

Kent County Council (2009) Elwick Road, Ashford: Automatic Traffic Speed/Volume Survey. Kent Highway Services, Maidstone, UK.

Methorst R (2007) Shared space: safe or dangerous? A contribution to objectification of a popular design philosophy. Proceedings of WALK21 Conference, Toronto, Canada, 1-3 October.
MVA Consultancy (2009) DfT Shared Space Project Stage 1: Appraisal of Shared Space. Department for Transport, London, UK.

MVA Consultancy (2010a) Designing the Future: Shared Space: Operational Research. Department for Transport, London, UK.

MVA Consultancy (2010b) Designing the Future: Shared Space: Qualitative Research. Department for Transport, London, UK.

NHL (2007) The Laweiplein: Evaluation of the Reconstruction into a Square with Roundabout. The NHL. University of Applied Sciences, Leeuwarden, the Netherlands. See http:// www.fietsberaad.nl/library/repository/bestanden/ Evaluation\%20Laweiplein.pdf (accessed 01/07/2011).

O'Rourke J (2011) Learning to Love Shared Space. Cambridgeshire Horizons, Cambridge, UK. See http:// www.cambridgeshirehorizons.co.uk/documents/farming/ learning\%20and\%20Development/1stFeb2011/ ashford_case_study_review.pdf (accessed 19/02/2013).

Quimby A and Castle J (2006) A Review of Simplified Streetscape Schemes. Transport Research Laboratory, Wokingham, UK, pp. $1-55$.

Robson C (2002) Real World Research. Blackwell Publishing, Padstow, UK.

Shared Space (2011) About Shared Space. See http:// www.shared-space.org (accessed 01/10/2011).

\section{WHAT DO YOU THINK?}

To discuss this paper, please email up to 500 words to the editor at journals@ice.org.uk. Your contribution will be forwarded to the author(s) for a reply and, if considered appropriate by the editorial panel, will be published as a discussion in a future issue of the journal.

Proceedings journals rely entirely on contributions sent in by civil engineering professionals, academics and students. Papers should be 2000-5000 words long (briefing papers should be 1000-2000 words long), with adequate illustrations and references. You can submit your paper online via www.icevirtuallibrary.com/content/journals, where you will also find detailed author guidelines. 